\title{
Normotensive Bilateral Pheochromocytoma with Lindau Disease: Case Report
}

\author{
Fumio OTSUKA, Toshio OGURA*, Minoru NAKAGAWA**, NobUHIKo HAYAKAWA, \\ HidEo KATAOKA, TETSUYA OISHI, AND HIROFUMI MAKINO \\ Department of Medicine III and **Department of Neurological Surgery, Okayama University Medical School, and \\ *Health and Medical Center, Okayama University, Okayama 700, Japan
}

\begin{abstract}
A 46-year-old man was found to have numerous cerebellar hemangioblastomas on magnetic resonance imaging (MRI). He denied any symptoms and had no history of hypertension, but his family history was remarkable for a father who died of renal cell carcinoma. Computed tomography (CT) of the abdomen revealed bilateral adrenal pheochromocytomas with significant enhancement in the regions where ${ }^{131} \mathrm{I}$-metaiodobenzylguanidine (MIBG) had noticeably accumulated. Endocrinological examinations demonstrated high plasma and urine catecholamine concentrations which were very responsive to metoclopramide and glucagon loading tests, without a significant change in blood pressure. After resection of bilateral pheochromocytomas, he underwent an operation for the cerebellar tumors. Since pheochromocytomas associated with Lindau or von Hippel-Lindau (VHL) disease have a tendency to multiple occurrence in normotensive patients, we suggest that patients with a family history involving VHL lesions should undergo cranial MRI, abdominal CT, MIBG scintigraphy and endocrinological examinations.
\end{abstract}

Key words: von Hippel-Lindau disease, Cerebellar hemangioblastoma, Renal cell carcinoma, MRI, ${ }^{131}$ Imetaiodobenzylguanidine (MIBG), Metoclopramide, Glucagon

(Endocrine Journal 43: 719-723, 1996)

LINDAU disease is a dominantly inherited disorder characterized by cerebellar hemangioblastomas. It is occasionally accompanied by retinal, brainstem and spinal cord hemangioblastomas, renal and pancreatic cysts and malignancies, pheochromocytomas, and epididymal cysts. The syndrome involving these lesions is also termed "von Hippel-Lindau (VHL) disease" [1-3]. Only 25 families with VHL have been reported in Japan [4]. The clinical diagnosis of VHL is often difficult because of the late onset of symptoms in affected individuals and the variety of organs involved [1-3,5]. We report the case of a normotensive patient with

Received: March 28, 1996

Accepted: June 24, 1996

Correspondence to: Dr. Fumio OTSUKA, Department of Medicine III, Okayama University Medical School, 2-5-1 Shikata-cho, Okayama city, Okayama 700, Japan
Lindau disease and bilateral pheochromocytomas, which were incidental findings on brain magnetic resonance imaging (MRI), computed tomography (CT) and ${ }^{131}$ I-metaiodobenzylguanidine (MIBG) scintigraphy.

\section{Case Report}

A 46-year-old Japanese man underwent cranial MRI examination due to a transient tinnitus. He had no symptoms or history of hypertension, but his family history was significant for a father who had died of renal cell carcinoma. In this family, there was no person manifesting VHL lesions except for the patient's father. MRI revealed numerous cerebellar tumors demonstrating homogeneous enhancement with Gd-DTPA on T1 weighted image (Fig. 1). Angiographic findings in 
the vertebral artery suggested hemangioblastomas (Fig. 2). Subsequent abdominal dynamic CT examination revealed bilateral adrenal tumors (Fig. 3). Physical examination on presentation was unremarkable, with a blood pressure of $140 / 80 \mathrm{~mm}$ $\mathrm{Hg}$, a pulse rate of $70 \mathrm{bpm}$ and ophthalmologically normal retinal findings. The blood pressure was consistently normal during close observation in the hospital, and no significant change in blood pressure in a day also was detected by ambulatory blood pressure monitoring (ABPM-630, COLIN Co, Aichi, Japan). Hematologic examinations demonstrated no abnormal findings (red blood cells, 484 $\times 10^{4} / \mathrm{mm}^{3}$; hemoglobin, $15.1 \mathrm{~g} / \mathrm{d} l$; platelets, 29.4 $\times 10^{4} / \mathrm{mm}^{3}$ ). Liver and renal function tests, serum lipids (total cholesterol, $179 \mathrm{mg} / \mathrm{dl}$; triglyceride, $85 \mathrm{mg} / \mathrm{d} l$ ), electrolytes, fasting blood sugar (104 $\mathrm{mg} / \mathrm{d} l)$, hemoglobin A1c (5.1\%) and urinalysis also were normal. Endocrinological examination revealed the following: plasma adrenaline, $0.06 \mathrm{ng} /$ $\mathrm{m} l$ (normal: $<0.1 \mathrm{ng} / \mathrm{ml}$ ); plasma noradrenaline, $1.6 \mathrm{ng} / \mathrm{ml}$ (normal: 0.05-0.40 $\mathrm{ng} / \mathrm{ml}$ ); plasma dopamine, $<0.2 \mathrm{ng} / \mathrm{ml}$ (normal: $<0.2 \mathrm{ng} / \mathrm{ml}$ ); urinary adrenaline, $20 \mu \mathrm{g} /$ day (normal: 3-23 $\mu \mathrm{g} /$ day); urinary noradrenaline, $279 \mu \mathrm{g} /$ day (normal: $25-$ $131 \mu \mathrm{g} /$ day); urinary dopamine, $1240 \mu \mathrm{g} /$ day (normal: $150-1000 \mu \mathrm{g} /$ day); and urinary vanillylmandelic acid, $9.5 \mathrm{mg} /$ day (normal: 3-8 mg/day). Adrenal function (serum cortisol, $11.7 \mu \mathrm{g} / \mathrm{d} l$; adrenocorticotropin, $25.6 \mathrm{pg} / \mathrm{ml}$ ) and thyroid function (free triiodothyronine, $4.54 \mathrm{pg} / \mathrm{ml}$; free thyroxine, $1.29 \mathrm{ng} / \mathrm{ml}$; thyroid stimulating hormone, $1.82 \mu \mathrm{U} / \mathrm{ml}$ ) were normal. The serum calcitonin concentration also was normal $(<10 \mathrm{pg} /$ $\mathrm{ml})$. These endocrinological examinations were followed by endocrinological stimulation tests with metoclopramide and glucagon. After the administration of metoclopramide (10 mg i.v.), of the three catecholamines, only plasma noradrenaline showed a transient increase (before, $1.6 \mathrm{ng} / \mathrm{ml} ; 2$ min after, $2.2 \mathrm{ng} / \mathrm{ml}$ ) without a change in blood pressure (Fig. $4 \mathrm{~A}$ ). In the case of glucagon ( $1 \mathrm{mg}$ i.v.), both noradrenaline (before, $0.8 \mathrm{ng} / \mathrm{ml} ; 2 \mathrm{~min}$ after, $1.1 \mathrm{ng} /$ $\mathrm{ml}$ ) and adrenaline (before, not detected; $2 \mathrm{~min}$ after, $0.7 \mathrm{ng} / \mathrm{ml}$ ) in plasma responded with an increase without a change in blood pressure (Fig. 4B). In both the $s$ is rulating tests, plasma catecholamines showed $\mathrm{f}$ eak values at 2 min after the administration and returned to the basal values in 7 min. MIBG scintigraphy exhibited a high accu-

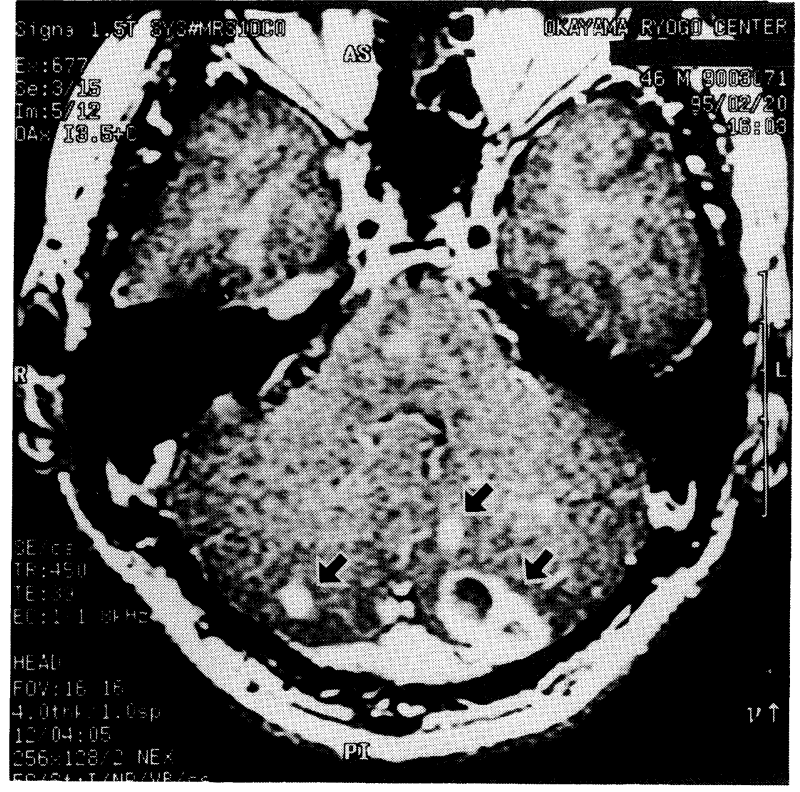

Fig. 1. Cranial magnetic resonance imaging (MRI) findings. Numerous cerebellar tumors were identified on cranial MRI. The tumors show signs of intense Gd-DTPA enhancement (arrows) on the T1 weighted image.

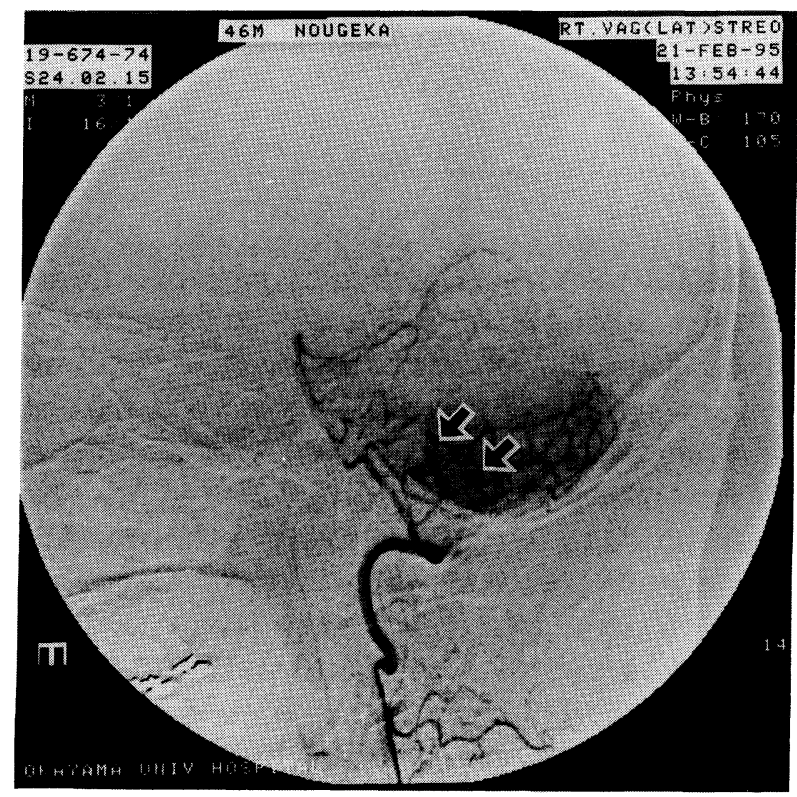

Fig. 2. Angiographic findings. Angiography of the vertebral artery showing numerous regions of tumor stain in the cerebellum (arrows). 


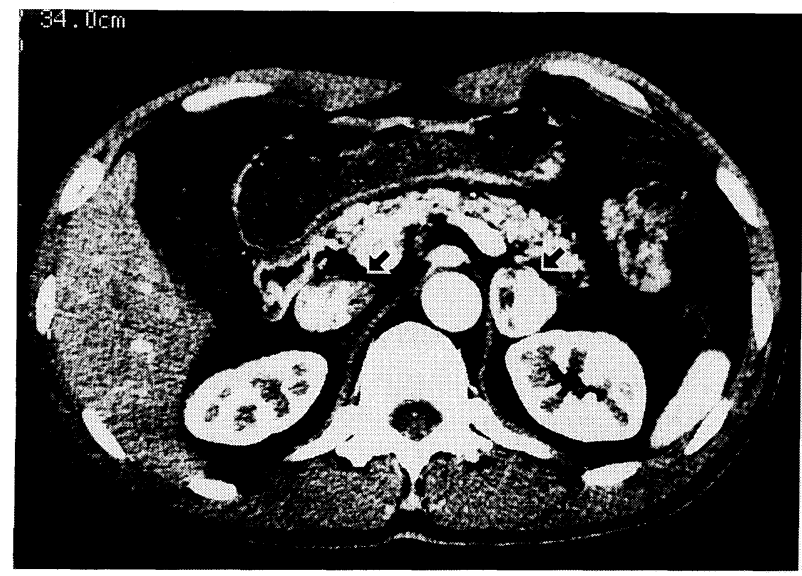

Fig. 3. Abdomial computed tomography (CT) findings. Bilateral adrenal tumors appear as high density lesions in the early enhancement phase (arrows).

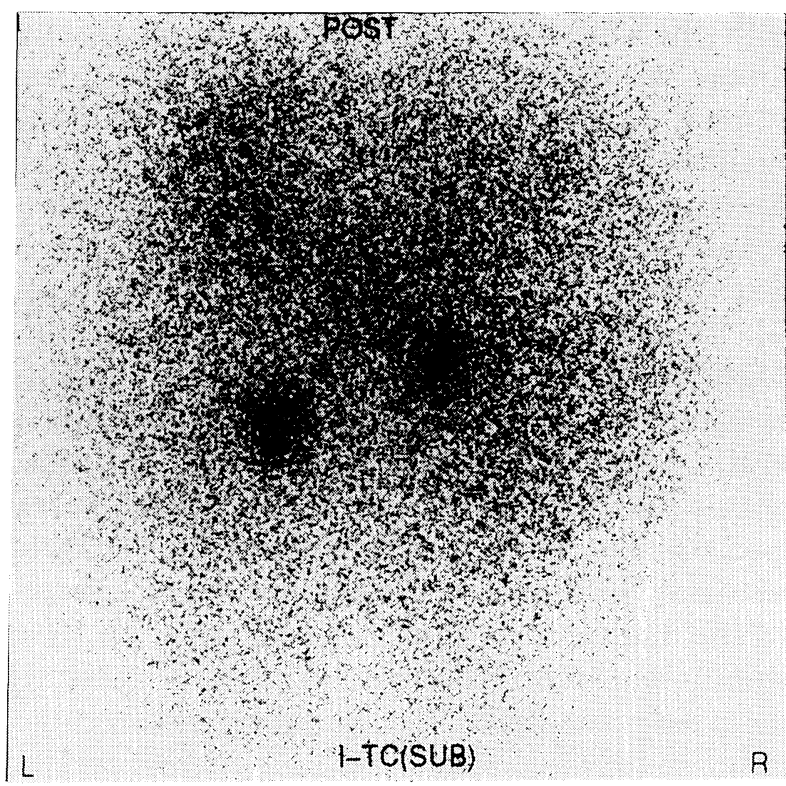

Fig. 5. Metaiodobenzylguanidine (MIBG) scintigraphy. A high accumulation of MIBG is seen in each adrenal tumor.

mulation of tracer in both adrenal glands (Fig. 5). On the basis of these radiographic findings and endocrinological data, the patient was diagnosed as having bilateral pheochromocytomas with Lindau disease. Spinal MRI revealed no abnormality. Bilateral adrenalectomy was performed, followed by surgery for resection of the cerebellar hemangioblastomas without postoperative complications. Histologically the resected adrenal tumors
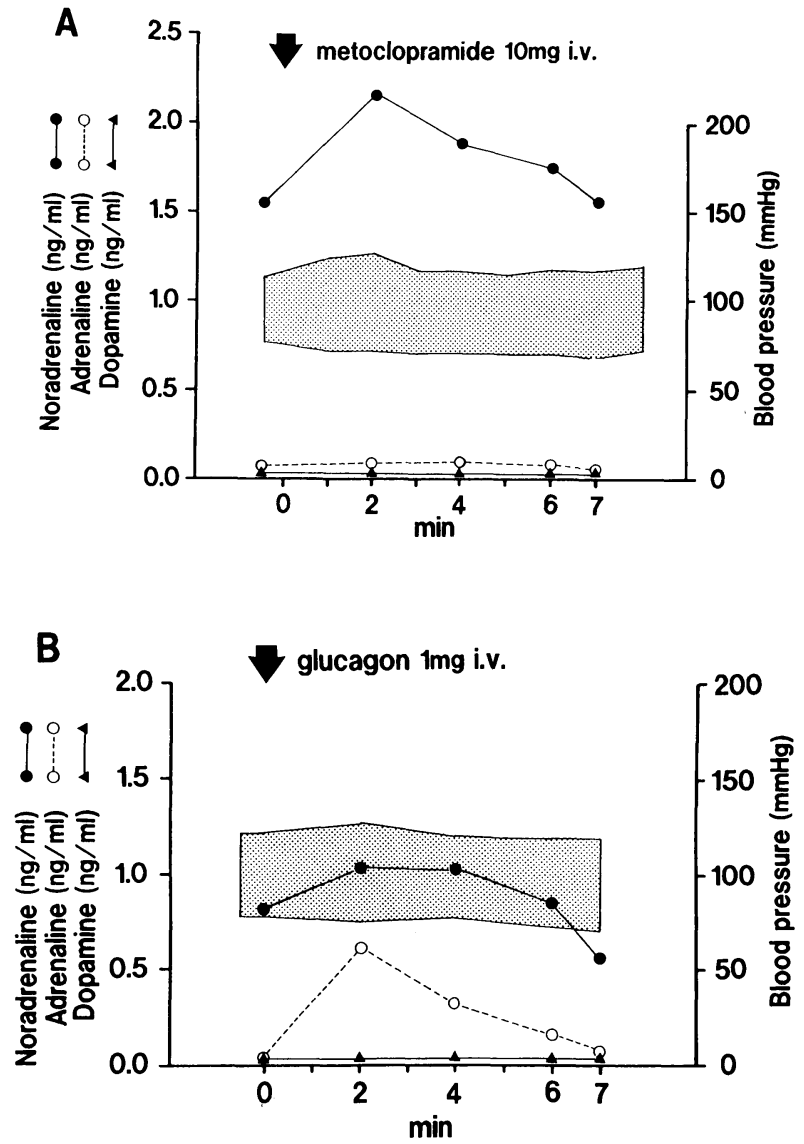

Fig. 4. Endocrinological stimulation tests. Metoclopramide administration induced an increase in the plasma noradrenaline concentration (A), and glucagon administration induced an increase in plasma noradrenaline and adrenaline concentrations (B). The blood pressure represented as a closed column showed no changes after the administration of either agent.

were proved to be pheochromocytomas composed of trabecular proliferation of polymorphic cells with chromaffin granules but no malignant findings, and the other resected cystic cerebellar tumors were compatible with hemangioblastoma composed of reticular capillary, cavernous vascular channels and vasoformative tissues. Replacement therapy with hydrocortisone ( $20 \mathrm{mg} /$ day) was initiated after surgery. Although right after the adrenectomy the blood pressure was transiently lowered, about 1 month after the surgery the blood pressure had remained at the preoperative value. He has since continued to do well with hormonal replacement. 


\section{Discussion}

In 1926, Avoid Lindau combined the "angiomatosis retinae" reported by von Hippel in 1895 and the "cerebellar hemangioblastoma," first described by Jackson in 1872, into one coherent entity. In addition to 24 reported cases, he described the cases of 16 patients with "central nervous system (CNS) angiomatosis" consisting of retinal, cerebellar and spinal hemangioblastomas; this condition was later termed "Lindau disease" [5]. Its major CNS features are termed "Lindau disease," and the entire syndrome has been termed "von Hippel-Lindau disease".

Von Hippel-Lindau disease is an autosomal dominant disorder characterized by a variety of manifestations, including hemangioblastomas of the retina (retinal angiomatosis), cerebellum (Lindau's tumor), medulla oblongata, and spinal cord; angiomas of the liver and kidney; adenomas of the kidney and epididymis; renal cell carcinoma; pheochromocytoma; and cysts of the pancreas, kidney, and epididymis [1, 2, 5]. Melmon and Rosen provided a broad definition for Lindau disease, even including patients with only a single lesion (Lindau complex); they also provided documentation of a CNS hemangioblastoma in at least one other family [5]. Although a maximum of 40 distinct lesions have been described in VHL, CNS hemangioblastomas, pheochromocytomas and renal cell carcinomas are the lesions which occasionally cause death. To reduce morbidity, early detection of asymptomatic lesions is critical, but these lesions are difficult to detect because of the late onset or lack of symptoms [1-3,5]. In the present case, incidental cranial MRI was helpful in identifying CNS lesions. Subsequent CT and MIBG scintigraphy examinations are also important in patients, even including those with Lindau complexes. Pheochromocytoma, which accounts for less than $1 \%$ of patients with systemic hypertension [7], is a feature of several disorders with an autosomal dominant pattern of inheritance, including multiple endocrine neoplasia (MEN)-type2, von Hippel-Lindau disease, and von Recklinghausen's disease. In patients with VHL lesions, the frequency of pheochromocytomas reportedly ranges from 5 to $60 \%[3,6]$. In one study of patients with pheochromocytomas, $23 \%$ were carriers of an inherent disorder, and 19\% had associated VHL disease [8]. These findings suggest that the disease manifestation of VHL lesions differs among races or families. In Japan, 17 of 103 cases composing VHL family were accompanied by pheochromocytoma [4], and this frequency is close to the $14 \%$ average in foreign reports [3,6].

Pheochromocytoma may be the only feature in a VHL patient [8]. Although it may cause hypertension, blood pressure instability, and headaches, patients with VHL tend to experience few symptoms [1]. Normal levels of catecholamines or their metabolites in these patients cannot rule out the presence of a pheochromocytoma [9], and pheochromocytomas are known to vary widely not only in size and clinical features, but also in the catecholamine production rate and metabolism [10]. Atuk et al. reported that 11 of 12 VHL patients with pheochromocytoma showed a significant increase in urine noradrenaline excretion but adrenaline was mildly increased in only 3 , and blood pressure was consistently normal in 5 middle-aged patients despite a persistent increase in noradrenaline, and the catecholamine contents of pheochromocytomas gradually decreased with age [6]. These findings suggest that the catecholamine degrading activity may increase or the sensitivity of adrenergic receptors may decrease with age in VHL associated pheochromocytoma [6, 11]. Also in this case, plasma and urine noradrenaline and metabolite concentrations were increased, and the results of catecholamine stimulating tests supported the diagnosis of pheochromocytoma. In these stimulating tests, however, we could not identify these responses as indicating a definite catecholamine producing tumor because of the lack of controls for comparison. The blood pressure in this patient was consistently normal despite the excessive noradrenaline excretion. In VHL patients, pheochromocytomas often remain quiescent, and biochemical and endocrinological tests or MIBG scans may yield normal results [1]. Since even biologically inactive phochromocytomas may suddenly become dangerous, resulting in a malignant change with associated mortality [1], the patient should be followed-up carefully with ultrasonograpy, CT and MRI.

In conclusion, affected individuals, including those with Lindau complexes, directly benefit from screening with MRI, CT and MIBG scintigraphy to 
make an early diagnosis. Inactive pheochromocytomas in patients with VHL, in particular, should be further investigated endocrinologically and morphologically. It is hoped that genetic screening will permit the earlier diagnosis of this disorder $[12,13]$, and will be helpful by being followed by target gene therapy.

\section{References}

1. Karsdorp N, Elderson A, Wittelbol-Post D, Hene RJ, Vos J, Feldberg MAM, van Gils APG, JansenSchillhorn van Veen JM, Vroom TM, Hoeppener JWM, Lips CJM (1994) Von Hippel-Lindau Disease: New strategies in early detection and treatment. Am J Med 97: 158-168.

2. Horton WA, Wong V, Eldridge R (1956) Von Hippel-Lindau disease: Clinical and pathological manifestations in nine families with 50 affected members. Arch Intern Med 136: 769-777.

3. Lamiell JM, Salazar FG, Hasia YE (1989) Von Hippel-Lindau disease affecting 43 members of a single kindred. Medicine (Baltimore) 68: 1-29.

4. Miyagami M, Miyagi A, Kido G, Satoh K, Tsubokawa T (1994) The two familial occurrence of von Hippel-Lindau disease. Brain and Nerve (Tokyo) 46: 683-689 (in Japanese).

5. Melmon KL, Rosen SW (1964) Lindau's disease: Review of literature and study of a large kindred. $\mathrm{Am}$ J Med 36: 595-617.

6. Atuk NO, McDonald T, Wood T, Carpenter JT, Walzak MP, Donaldson M, illenwater JY, Turner S, Westfall V (1979) Familial pheochromocytoma, hypercalcemia and von Hippel-Lindau disease: A ten-year study of a large family. Medicine (Baltimore) 58: 209-218.

7. Manger WM, Gifford RW (1978) Current concepts of pheochromocytoma. Cardiovasc Med 3: 289-294.

8. Neumann HPH, Berger DP, Sigmund G, Blum U, Schmidt D, Parmer RJ, Volk B, Kirste G (1993) Pheochromocytomas, multiple endocrine neoplasia type 2, and von Hippel-Lindau disease. New Engl J Med
329: 1531-1538.

9. Cryer PE (1984) Pheochromocytomas. Clin Endocrinol Metab 14: 203-220.

10. Crout JR, Sjoerdsma A (1964) Turnover and metabolism of catecholamines in patients with pheochromocytoma. J Clin Invest 43: 94-102.

11. Engelman K, Horwitz D, Ambrose IM, Sjoerdsma A (1968) Further evaluation of the tyramine tests for pheochromocytomas. New Engl J Med 278: 705709.

12. Seizinger BR, Rouleau GA, Ozelius LJ, Lane AH, Farmer GE, Lamiel JM, Hains J, Yuen JWM, Collins D, Majoor-Krakauer D, Bonner T, Mathew C, Rubenstein A, Halperin J, McConkie-Rosell A, Green JS, Trofatter JA, Ponder BA, Eierman L, Bowmer MI, Schimke R, Oostra B, Aronin N, Smith DI, Drabkin H, Waziri MH, Hobbs WJ, Martuza RL, Conneally PM, Hsia YE, Gusella JF (1988) Von Hippel-Lindau disease maps to the region of chromosome 3 associated with renal cell carcinoma. Nature 332: 268-269.

13. Latif F, Tory K, Gnarra J, Yao M, Duh FM, Orcutt ML, Stackhouse T, Kuzmin I, Modi W, Geil L, Schmidt L, Zhou F, Li H, Wei MH, Chen F, Glenn G, Choyke P, Walther MM, Weng Y, Duan DSR, Dean M, Glavac D, Richards FM, Crossey PA, Ferguson-Smith MA, Paslier DL, Chumakov I, Cohen D, Chinault AC, Maher ER, Linehan WM, Zbar B, Lerman MI (1993) Identification of the von Hippel-Lindau disease tumor suppessor gene. Science 260: 1317-1320. 